\title{
Pattern of Histopathologically Confirmed Uterine and Ovarian Anomeli Among 98 Hysterectomies Attending a Private Medical College Hospital, Dhaka
}

\author{
*TT Sajani ${ }^{1}$, TT Sarnali ${ }^{2}$, MA Rahman ${ }^{3}$, S Ahmed $^{4}$ \\ $1 *$ Dr. Tabassum Tahmin Sajani, Ex-Assistant Professor, Community Medicine, Anwer Khan Modern Medical College \\ ${ }^{2}$ Dr. Tanjila Tahmin Sarnali, MD thesis part student, Department of Pathology, Dhaka Medical College \\ ${ }^{3}$ Dr. Md. Atiqur Rahman, Associate Professor, Department of Community Medicine, Anwer Khan Modern Medical College \\ ${ }^{4}$ Dr. Shoib Ahmed, Intern Doctor, Anwer Khan Modern Medical College Hospital \\ *Corresponding Author
}

Date of submission: 22.03.2016 Date of acceptance: 15.10 .2016

\begin{abstract}
Background: Endometrial diseases ranked among the most common gynecological disorders that affect women globally. This study was undertaken to identify the most common pathologies identified in hysterectomy specimens.

Materials \& Methods: The present study was conducted in the Department of Pathology, Anwer Khan Modern Medical College, Dhaka over a period of 6 months from July to December 2013. Ninety eight (98) hysterectomy specimens were received by the pathology department during this period. On receiving the hysterectomy specimens, the gross features were noted. A detailed microscopic examination was done to arrive at an accurate diagnosis.

Result: Most of the women 54\% were 40-49 years age group followed by $25 \%$ in 30-39 years age group. Chronic cervicitis and adenomyosis were the commonest pathological findings in $(80.6 \%)$ and $(32.7 \%)$ respectively. Other pathologies identified include Leiomyoma (23.5\%), endometrial hyperplasia (17.4\%), endometrial polyp (4.1\%) and PID with hemorrhagic infection $(1.0 \%)$. Two cases of carcinoma cervix (2.0\%), two local invasion of tumors $(2.0 \%)$ and one adenocarcima $(1.0 \%)$ was found. Type of operation most common is total hysterectomy with oophorectomy $(51.0 \%)$.

Conclusion: Hysterectomy still remains the widely used treatment modality even in developed countries. The ultimate diagnosis is only on histology, so every hysterectomy specimen should be subjected to histopathological examination. Benign pathologies are more common than their malignant counterparts and the most common pathologies identified in hysterectomy specimens are chronic cervicitis, adenomyosis and leiomyoma.
\end{abstract}

Key Words: Histopathology, Endometrial diseases, cervicitis, adenomyosis, leiomyoma

\section{Introduction}

Endometrial diseases ranked among the most common gynecological disorders that affect women globally. ${ }^{1}$ These diseases cut across all age groups and contribute significantly to increased maternal morbidity and mortality. ${ }^{1}$ Studies have shown that histopathological patterns of diagnosis varies with respect to the age of patients. $^{2}$ Most young women of reproductive age present more commonly with changes associated with hormonal imbalance. ${ }^{2}$ However, older women of premenopausal and postmenopausal age group present more commonly with endometrial hyperplasia and endometrial carcinoma. ${ }^{2,3}$

AKMMC J 2017; 8(1) : 06-09
Hysterectomy is one of the common surgical procedures in peri and postmenopausal women; it is the second most common surgical procedure in USA. ${ }^{4}$ According to the center of disease prevention and control about 5 out of every 1000 women undergo hysterectomy each year in USA. ${ }^{5}$

Hysterectomy is considered a life saving procedure in women with certain types of cancer and in acute uterine hemorrhage. It also improves the quality of life for women with certain uterine pathologies such as fibroids, endometriosis and uterine prolapse. With accurate selection of patients and the route of 
Pattern of Histopathologically Confirmed Uterine and Ovarian Anomeli hysterectomy, morbidity and mortality is low. ${ }^{5}$ To the best of our knowledge up-to-date data is lacking about histological pattern of hysterectomies in Bangladeshi women. This study was undertaken to identify the most common pathologies identified in hysterectomy specimens. 98 cases, over a period from July 2013 to December 2013 formed the subject for the present study. This study confirms that benign pathologies are more common in hysterectomy specimens than their malignant counterparts among Bangladeshi women.

\section{Materials and Method}

The present study was conducted in the Department of Pathology, Anwer Khan Modern Medical College, Dhaka over a period of 6 months from July to December 2013. Ninety eight (98) hysterectomy specimens were received by the pathology department during this period. On receiving the hysterectomy specimens, the gross features were noted. Multiple bits were taken from the representative sites, processed and paraffin blocks were made. The blocks were sectioned and stained with hematoxylin and eosin. A detailed microscopic examination was done to arrive at an accurate diagnosis. In cases of more than one pathologic diagnosis, both diagnoses were counted by including them separately in their assigned category. Patient's age, histopathologically confirmed diagnosis as well as the type of hysterectomy were reviewed.

The data was analyzed using SPSS 19 version. Descriptive statistics were used to describe data.

\section{Results}

Hysterectomies were distributed over a wide age ranging from 26 years to 70 years with mean age 43.61 \pm 7.7 . In 6 months duration, total 98 hysterectomy specimens received in the Pathology department of Anwer Khan Modern Medical College. Of these, most of the women 54\% were 40-49 years age group followed by $25 \%$ in 30-39 years age group. (Figure-1)

On histopathology in many hysterectomy specimens, more than one type of pathology was found. Chronic cervicitis and adenomyosis were the commonest pathological findings in ( 80.6\%) and (32.7\%) respectively as illustrated in Table 1 . Other pathologies identified include Leiomyoma (23.5\%), endometrial hyperplasia (17.4\%), endometrial polyp (4.1\%) and
PID with hemorrhagic infection (1.0\%). (Table -1)

Two cases of carcinoma cervix $(2.0 \%)$, two local invasion of tumors $(2.0 \%)$ and one adenocarcima $(1.0 \%)$ was found. Type of operation most common is total hysterectomy with oophorectomy (51.0\%) followed by total hysterectomy without oophorectomy $(45.9 \%)$ and subtotal hysterectomy (3.0\%)(Figure-2)

Oophorectomy was common in age group 40-49 years $(58 \%)$ and $30-39$ years (20\%). (Fig-3)

Among benign ovarian disorder, simple cyst $4.1 \%$, serous cystadenoma $3.1 \%$, cystic teratoma $2.0 \%$,mucinous cystadenoma $1.0 \%$. And in malignant counterpart secondary tumour invasion $2.0 \%$ and clear cell adenacarcinoma $1.0 \%$.

Table I: Histological types

\begin{tabular}{ll}
\hline Histological types & Frequency (\%) \\
\hline Cervix and uterus & \\
Chronic cervicitis & $79(80.6)$ \\
Chronic cervicitis with & $03(3.1 \%)$ \\
squamous metaplasia & \\
Chronic cervicitis with & $03(31 \%)$ \\
hyperkeratosis & \\
Carcinoma cervix & $02(2.0 \%)$ \\
Proliferative endometrium & $40(40.8 \%)$ \\
Secretory endometrium & $11(11.2 \%)$ \\
Simple endometrial & $17(17.35 \%)$ \\
hyperplasia & \\
Endometrial polyp & $04(4.1 \%)$ \\
Adenomyosis & $32(32.7 \%)$ \\
Leiomyoma & $23(23.5 \%)$ \\
PID with haemorrhagic & $01(1 \%)$ \\
infection & \\
Senile cystic atrophy & $02(2.0 \%)$ \\
Adenocarcinoma & \\
Secondary tumour & $02(3.1 \%)$ \\
invasion & $01(1 \%)$ \\
Ovary & $02(2 \%)$ \\
Simple cyst & \\
Serous cystadenoma & \\
Mucinous cystadenoma & \\
Cystic teratoma & \\
Clear cell & \\
adenocarcinoma & \\
invasion & \\
\hline
\end{tabular}




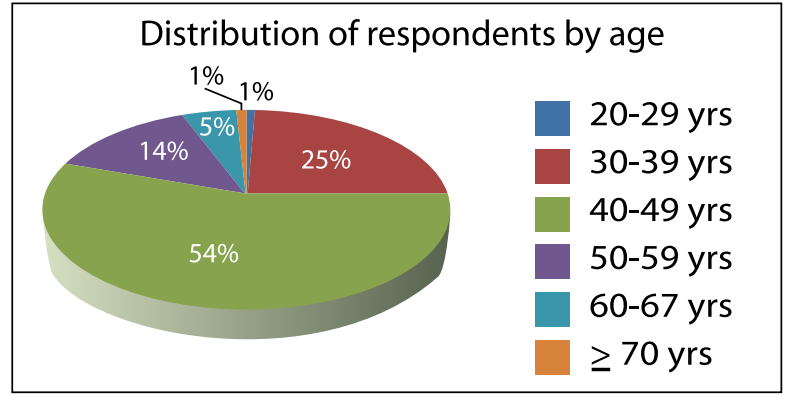

Figure-1

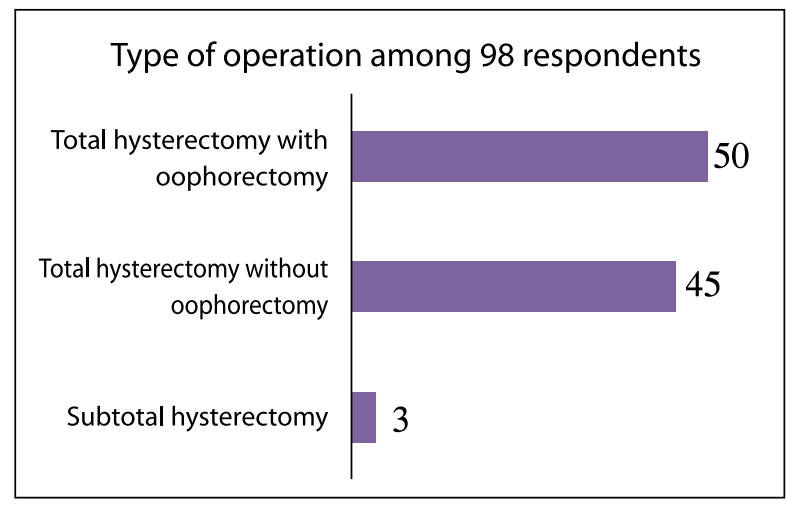

Figure-2

Age distribution of 50 cases having oophorectomy

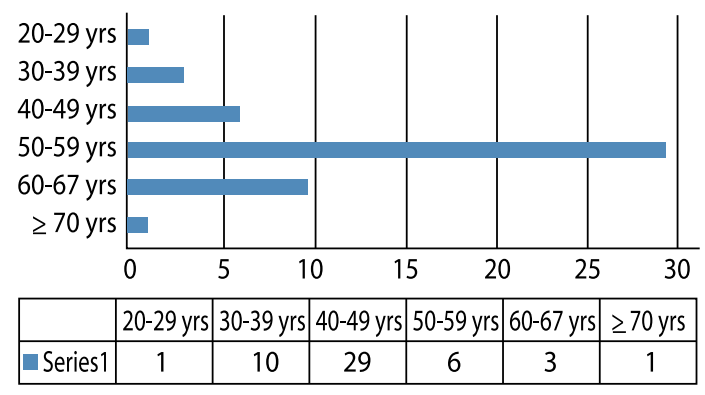

Figure-3

\section{Discussion}

The mean age at hysterectomy in this study was 43.61years. Hysterectomies were distributed over a wide age ranging from 20 years to 80 years in a study of 500 hysterectomies. Of this fifty-two percent $(51.40 \%)$ cases were encountered in $40-49$ years which is the most common age group. ${ }^{6}$ According to data of Center for Disease Control (1994-1999) approximately 600,000 hysterectomies are performed annually in the United States and an estimated 20 million U.S women have had a hysterectomy. Women aged 40-44 years had a significantly higher hysterectomy rate compared with any other age group in the U.S and $52 \%$ of all hysterectomies were performed among women aged $<44$ years. ${ }^{7}$ Since early $20^{\text {th }}$ century,hysterectomy is a definitive treatment of pelvic pathology including fibroid, abnormal heavy bleeding, chronic pelvic pain, endometriosis, adenomyosis, uterine prolapsed, pelvic inflammatory disease and cancer of reproductive organs. ${ }^{8}$ A study in Tehran showed $40.1 \%$ women of 45-55 years had hysterectomy operations. ${ }^{9}$

Adenomyosis and leiomyoma are commonest pathology seen in this study which is similar with many other studies. Incidence of leiomyoma $25.8 \%$ in Saudi Arab, $78 \%$ in USA, $48 \%$ in Nigeria and $8 \%$ in Sweden. ${ }^{10,11,12,13}$

In a study by Gupta $\mathrm{G}$, adenomyosis, endometrial polyp and ovarian cyst were $10.9 \%, 1 \%$ and $2.8 \%$ respectively. ${ }^{14}$ In study 1 endometrial polyp was $3 \%$ which is a bit lower than our study findings (4.1\%).

A study by 1 showed Proliferating endometrium $22.5 \%$, secretory endometrium $19.9 \%$, and simple endometrial hyperplasia $10.0 \%$. Similar report was documented for proliferating $(21.7 \%)$ and secretory endometrium (12.4\%) by other researchers. ${ }^{15,16,17}$

Findings for proliferating endometrium is much higher in our study, $40.8 \%$ but secretory endometrium more or less similar $11.2 \%$.

In our study endometrial polyp $4.1 \%$, endometrial hyperplasia $17.35 \%$ and endometrial carcinoma $1.0 \%$. The results are similar with other studies. Gerald D observed endometrial polyp 3\% cases $^{6}$, Muzzafar et al reported endometrial hyperplasia in $18.3 \%$ case 18 and Sarwa et al showed endometrial carcinoma in $1.7 \%$ case $^{1}$. A lower value $0.5 \%$ observed by Jairajpuri et al. ${ }^{19}$

\section{Conclusion}

Hysterectomy still remains the widely used treatment modality even in developed countries. The ultimate diagnosis is only on histology, so every hysterectomy specimen should be subjected to histopathological examination. Benign pathologies are more common than their malignant counterparts and the most common pathologies identified in hysterectomy specimens are chronic cervicitis, adenomyosis and leiomyoma. 
Pattern of Histopathologically Confirmed Uterine and Ovarian Anomeli

\section{Conflict of Interest: none}

\section{References}

1. Sawer A, Haque A. Types and frequencies of pathologies in endometrial curretings of abnormal uterine bleeding. Int $\mathrm{J}$ Pathol 2005; 3: 65-70.

2. ACOG committee on practice Bulletin-Gynecology. American college of Obstetricians and Gynecologists. ACOG practice bulletin: Management of anovulatory bleeding. Int $\mathrm{J}$ Gynaecol Obstet 2001; 72: 263-71 .

3. Jemal A, Bray F, Center MM, Ferlay J, ward E, Forman D. Global cancer statistics. CA cancer J Clin 2011; 61: 69-90.

4. Graves, EJ. National Center for Health Statistics, National Hospital discharge survey: annual summary, 1990 .Viral Health Stat (13). 1992, No-112. DHHS publication PHS 921773.

5. Layla S A, Hysterectomy: A Clinicopathologic correlation. Bahrain Medical Bulletin 2014; 28 (2).

6. Gerald D, Jonathan U. Histopathological Patterns of Endometrial Lesions in Patients with Abnormal Uterine Bleeding in a Cosmopolitan Population. Journal of Basic and Clinical Reproductive Sciences, July-December 2013; 2(2): 101-104.

7. Kashavarz H, Hillis S, kiele BA, Marchbanks PA. Hysterectomy surveillance-united state, 1994 - 1999 MMWR CDC. Surveiillance Sum 2002; 511-8.

8. Nausheen F, Iqbal J, Bhatti FA, Khan AT and Sheikh S. Hysterectomy: The patient's perspective. Annals Gynecol 2004; 10: 339-41.

9. Mohmoud Khaniki, Mahsa Shojaie, Azam M Tarafdari. Histopathological study of Hysterecomy operations in A University Clinic in Tehran from 2005 to 2010. (Unpublished)
11. Baird DD, Dunson DB, Hill MC, Cousins D, Schectman JM. High cumulative incidence of uterine leiomyoma in black and white women: Ultrasound eveidence. Am J Onstet Gynecol 2003; 188: 100-7.

10. Sobande AA, Eskander M, Archibong EI, Damole IO. Elective hysterectomy: A clinicopathological review from Abha catchment area of Saudi Arabia. West Afr J Med 2005; 24: $31-5$.

12. Adelusola KA, Ogunniyi SO. Hysterectomies in Nigerians; histopathological analysis of cases seen in Ile-Ife. Niger Postgrad Med J 2001; 8: 37-40.

13. Borgfeldt C, Andolf E. Transvaginal ultrasono-graphic findings seen in the uterus and the endometrium: Low prevalence of leiomyoma in a random sample of women age 25-40. Acta Obstet Gynecol Scand 2000; 79: 202-7.

15. Gupta G, Kotasthane D, Kotasthane V. Hysterectomy: A clinico-pathological Correlation of 500 cases. Journal of basic and reproductive science 2012; 1(1).

16. Bhosle A, Fonseca M. Evaluation and histopathological correlation of abnormal uterine bleeding in perimenopausal women. Bombay Hosp J 2010; 52: 69-72.

17. Takreem A, Danish N, Razaq S. Incidence of endometrial hyperplasia in 100 cases presenting with polymenorrhagia/menorrhagia in perimenupausal women. J Ayub Med Coll Abbottabad 2009; 21: 60-3.

18. Muzaffar M, Akhtar KA, Yasmin S, Mahmood-Ur-Rahman, Iqbal W, Khan MA. Menstrual irregularities with excessive blood loss: A Clinico-pathological correlation. J Park Med Assoc 2005; 55: 486-9.

19. Jairajpuri ZS, Rana S, Jetley S. Atypical uterine bleeding histopathological audit of endometrium. A study of 638 cases. Al Ameen J Med Sci 2013; 6: 21-2. 